Gut and Liver, Vol. 10, No. 4, July 2016, pp. 624-631

\title{
Ascitic Fluid Calprotectin and Serum Procalcitonin as Accurate Diagnostic Markers for Spontaneous Bacterial Peritonitis
}

\author{
Ahmed Abdel-Razik ${ }^{1}$, Nasser Mousa ${ }^{1}$, Dina Elhammady ${ }^{1}$, Rania Elhelaly ${ }^{2}$, Rasha Elzehery ${ }^{2}$, Sherif Elbaz $^{3}$, Mohamed \\ Eissa $^{4}$, Niveen El-Wakeel ${ }^{5}$, and Waleed Eldars ${ }^{5}$ \\ Departments of ${ }^{1}$ Tropical Medicine, ${ }^{2}$ Clinical Pathology, Mansoura University, Mansoura, ${ }^{3}$ Department of Endemic Diseases and \\ Gastroenterology, Aswan University, Aswan, ${ }^{4}$ Department of Internal Medicine, Faculty of Medicine, Mansoura University, and ${ }^{5}$ Department of \\ Medical Microbiology and Immunology, Mansoura University, Mansoura, Egypt
}

Background/Aims: The diagnosis of spontaneous bacterial peritonitis (SBP) is based on a polymorphonuclear leukocytes (PMNs) exceeding 250/ $\mu \mathrm{L}$ in ascitic fluid. The aim of the study was to evaluate serum procalcitonin and ascitic fluid calprotectin as accurate diagnostic markers for detecting SBP. Methods: Seventy-nine patients with cirrhotic ascites were included. They were divided into a SBP group, including 52 patients, and a non-SBP group of 27 patients. Serum procalcitonin, ascitic calprotectin, and serum and ascitic levels of tumor necrosis factor $\alpha$ (TNF- $\alpha$ ) and interleukin 6 (IL6) were measured using an enzyme-linked immunosorbent assay. Results: Serum procalcitonin and ascitic calprotectin were significantly higher in SBP patients than in non-SBP patients. Significant increases in both serum and ascitic levels of TNF- $\alpha$ and IL-6 were observed in SBP patients versus nonSBP patients. At a cutoff value of $0.94 \mathrm{ng} / \mathrm{mL}$, serum procalcitonin had $94.3 \%$ sensitivity and $91.8 \%$ specificity for detecting SBP. In addition, at a cutoff value of $445 \mathrm{ng} / \mathrm{mL}$, ascitic calprotectin had $95.4 \%$ sensitivity and $85.2 \%$ specificity for detecting SBP. Both were positively correlated with ascitic fluid proteins, PMN count, TNF- $\alpha$, and IL-6. Conclusions: ACcording to our findings, determination of serum procalcitonin levels and ascitic calprotectin appears to provide satisfactory diagnostic markers for the diagnosis of SBP. (Gut Liver 2016;10:624-631)

Key Words: Calprotectin; Interleukin-6; Procalcitonin; Spontaneous bacterial peritonitis; Tumor necrosis factor-alpha

\section{INTRODUCTION}

Patients with chronic liver failure, who have an impaired im- mune status, are often highly susceptible to infections such as urinary tract infection, spontaneous bacterial peritonitis (SBP), respiratory tract infection, bacteremia ${ }^{1}$ and Cryptosporidium that has emerged as a significant human pathogen worldwide and as a cause of diarrhea in patients with chronic liver diseases. ${ }^{2-4}$

SBP is an important cause of morbidity and mortality in cirrhotic patients with ascites. SBP is estimated to affect $10 \%$ to $30 \%$ of cirrhotic patients hospitalized with ascites, with a mortality rate approaches $30 \%{ }^{5}$ Procalcitonin (PCT) is a peptide precursor of the hormone calcitonin, which is involved in calcium homeostasis. It is composed of 116 amino acids and is produced by parafollicular cells ( $C$ cells) of the thyroid and by the neuroendocrine cells of the intestine and the lung. The level of PCT in the blood stream of healthy individuals is below the limit of detection $(10 \mathrm{pg} / \mathrm{mL})$ of clinical assessment. The level of PCT rises in a response to a proinflammatory stimuli, especially of bacterial origin. ${ }^{6}$ Based on its rapid detection within 2 hours or as a recently available bedside test at moderate cost. Serum PCT determination seems to add some characteristics to the traditional cell count for the diagnosis of SBP, especially in the absence of another site of infection all over the body, through providing valuable information immediately by a noninvasive diagnostic test in ascitic patients. ${ }^{7}$

Calprotectin is calcium and zinc-binding protein which is detected almost exclusively in neutrophils, ${ }^{8}$ and its presence in body fluids is proportional to the influx of neutrophils. ${ }^{9}$

Ascitic fluid calprotectin reliably predicts polymorphonuclear leukocytes (PMNs) count $>250 / \mathrm{mm}^{3}$, which may provide a useful marker for the diagnosis of SBP, especially with a readily available bedside testing device. $^{10}$

SBP is associated with production of inflammatory mediators. ${ }^{11}$ In these patients proinflammatory cytokines (tumor ne-

Correspondence to: Nasser Mousa

Department of Tropical Medicine, Mansoura University, El Gomhoria Street, Mansoura 35516, Egypt

Tel: +20-01227029213, E-mail: Mousa_medic@yahoo.com

Received on March 9, 2015. Revised on July 4, 2015. Accepted on July 6, 2015. Published online November 27, 2015

pISSN 1976-2283 eISSN 2005-1212 http://dx.doi.org/10.5009/gnl15120

@) This is an Open Access article distributed under the terms of the Creative Commons Attribution Non-Commercial License (http://creativecommons.org/licenses/by-nc/4.0) which permits unrestricted non-commercial use, distribution, and reproduction in any medium, provided the original work is properly cited. 
crosis factor $\alpha$ [TNF- $\alpha$ ] and interleukin 6 [IL-6]) are released to blood and ascites, in response to hepatic injury. ${ }^{12}$

This work was planned aiming to evaluate the role of serum PCT and ascitic fluid calprotectin and their relationship with proinflammatory cytokines (TNF- $\alpha$ and IL-6) as accurate diagnostic laboratory markers for detecting SBP.

\section{MATERIALS AND METHODS}

In this prospective study, we recruited consecutive 122 patients with ascites referred for paracentesis to the Tropical Medicine, Internal Medicine Department Mansoura University and Endemic Diseases and Gastroenterology Department, Aswan University, Egypt from April 2013 to May 2014. All patients were subjected to the following evaluations: complete history taking and physical examination, abdominal ultrasound, laboratory assessment, and ascitic fluid analysis (PMNs, protein, bacteriologic culture and sensitivity).

As a routine procedure, diagnostic paracentesis of ascitic fluid was performed for all patients with ascites and liver cirrhosis who was admitted to our department, independent of the clinical suspicion of ascitic fluid infection (AFI). Thus, its diagnosis was made on the basis of the presence of at least 250 cells $/ \mathrm{mL}$ PMN in the ascitic fluid, with or without positive ascitic fluid culture in the absence of secondary peritonitis and hemorrhagic ascites.

Exclusion criteria included patients who were immunocompromised and patients who had received antibiotic on prophylactic for SBP or prior to hospital admission. Moreover, patients with neoplastic disorders, with clinically overt hyper or hypothyroidism or with laboratory and clinically evident autoimmune diseases, hematological disorders, diabetes mellitus, peripheral vascular disease, hypertension, hyperlipidemia, heart failure, and sepsis as well as other bacterial infection among patients with cirrhosis were also excluded from this study. None of the study participants had received nonsteroidal antiinflammatory drugs (NSAIDs), oral contraceptive drugs, and anticoagulant medications before hospital admission. Other unrelated possibilities that may affect the levels of cytokines were excluded, e.g., inflammatory conditions and infection.

\section{Sampling}

(1) Five-milliliter blood was withdrawn by venipuncture, 1 $\mathrm{mL}$ on ethylenediaminetetraacetic acid for $\mathrm{CBC}$ and $4 \mathrm{~mL}$ without anticoagulant. Serum samples were divided into aliquots and frozen at $-20^{\circ} \mathrm{C}$ until analysis.

(2) Samples of ascitic fluid were taken by diagnostic paracentesis performed under complete aseptic conditions from a puncture site in the right or left lower quadrant with the patient in the supine resting position. Twenty milliliters of ascitic fluid was obtained from all patients. Then, $10 \mathrm{~mL}$ was inoculated in aerobic blood culture bottles (Egyptian Diagnostic Media, Cairo,
Egypt) at the bedside. ${ }^{13}$ The rest of ascitic fluid samples was transferred immediately to the laboratory.

\section{Methodology}

Liver profile, blood glucose, and creatinine concentrations were measured on Hitachi 902 Chemistry autoanalyzer (Roche Diagnostics, Basel, Switzerland) using its commercially available reagents, complete blood picture was measured on CELLDYN Emerald cell counter (ABBOTT, Wiesbaden, Germany), serum PCT was measured quantitatively by enzyme-linked immunosorbent assay (ELISA) technique using RayBio ${ }^{\circledR}$ Human PCT ELISA kit (RayBiotech Inc., Norcross, GA, USA). This assay employs an antibody specific for human PCT coated on a 96well plate. The reference value was up to $0.5 \mathrm{ng} / \mathrm{mL}$, ascitic fluid calprotectin was measured by an ELISA using immune diagnostic AG ELISA kit (MRP 8/14; Immundiagnostik AG, Bensheim, Germany), as well as, TNF- $\alpha$ and IL- 6 were measured by an ELISA using kits supplied by DIAsource (Louvain la Neuve, Belgium). According to the measuring kits, TNF- $\alpha$ ranged between 4.6 and $12.4 \mathrm{pg} / \mathrm{mL}$ and IL-6 ranged between 0 and $50 \mathrm{pg} / \mathrm{mL}$.

Ascitic fluid analysis aspirated uninoculated ascitic fluid was collected in ethylenediaminetetraacetic acid tubes and analyzed within 3 hours of aspiration. A small portion of ascitic fluid was centrifuged in the lab for 3 to 5 minutes and analyzed for glucose levels and total proteins. Then a smear prepared from the deposit was stained with Gram. In addition, differential and total leukocyte counts were determined directly from uncentrifugated portion. Regarding microbiological examination, inoculated blood culture bottles were incubated for 3 successive days at $37^{\circ} \mathrm{C}$ with daily subculture on blood, MacConkey and chocolate agars. Antimicrobial susceptibility testing and bacterial identification were carried out using standard procedures. ${ }^{14}$

\section{Ethics}

This study was approved by the Ethical Committee of Mansoura University and all patients provided written informed consent prior to participation in any protocol-specific procedures. The study was conducted in accordance with the guidelines of the Helsinki Declaration.

\section{Statistical analysis}

All statistical analyses were performed using the SPSS version 17.0 software (SPSS Inc., Chicago, IL, USA). KolmogorovSmirnov test was used to test distribution of data. Parametric data were expressed in mean \pm standard deviation. Whereas, none parametric data were expressed in the form of median (minimum-maximum). Student t-test and Mann-Whitney U test were used for intergroup comparisons. Analysis of the receiver operator characteristics (ROC) and calculation of the area under the receiver operating characteristic curve (AUC) were used to evaluate serum PCT, ascitic calprotectin, TNF- $\alpha$ and IL- 6 with maximum sensitivity and specificity for differentiation between 
ascitic patients with AFI and others without AFI. Spearman correlation analysis was done between serum PCT and ascitic calprotectin levels with serum and/or ascitic proinflammatory cytokines. A p-value of less than or equal 0.05 indicated statistical significance.

\section{RESULTS}

\section{Patient characteristics}

From consecutive 122 ascitic patients, only 79 patients without any infection in other organs or sites were included in this study. The final diagnosis of SBP and the etiology of ascites were assessed. According to ascitic fluid analysis and clinical data, patients were divided into SBP group, including 52 patients (38 males and 14 females) and non-SBP group (control group) of 27 patients (21 males and six females). Forty-three patients were excluded from the study; 16 patients had malignant ascites (which included eight patients with leaking hepatocellular carcinoma, two patients with ovarian cancer, two patients with lymphomas, one patient with breast cancer, one patient with stomach cancer, one patient with colorectal cancer, and one patient with pancreatic cancer); 20 patients who had received antibiotic prior to hospital admission and seven patients with skin infections (Fig. 1).

\section{Ascitic patients were screened}

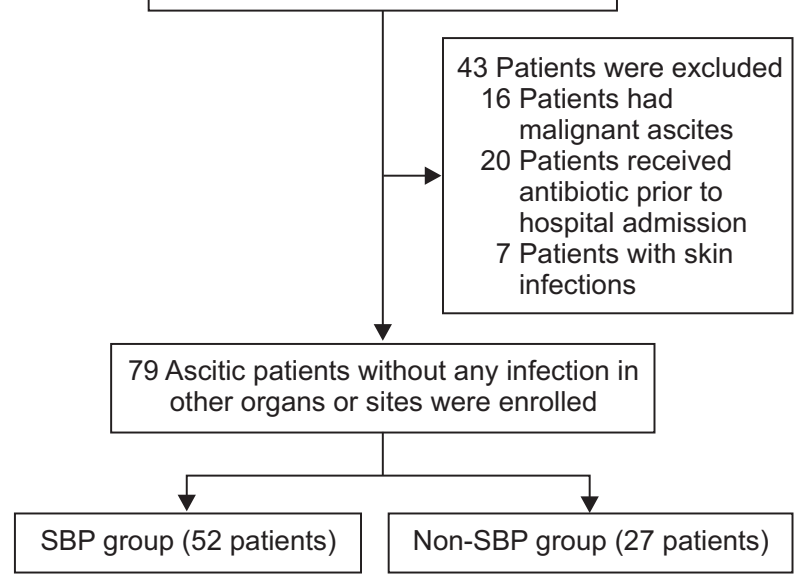

Fig. 1. Study algorithm.

SBP, spontaneous bacterial peritonitis.

Table 1. Demographic Data, Clinical Characteristics, and Laboratory Findings in the Studied Groups

\begin{tabular}{|c|c|c|c|}
\hline Variable & $\operatorname{SBP}(n=52)$ & Non-SBP (n=27) & p-value \\
\hline Age, yr & $58.4 \pm 10.2$ & $57.5 \pm 10.7$ & 0.76 \\
\hline Sex, male/female & $38 / 14$ & $21 / 6$ & 0.55 \\
\hline \multicolumn{4}{|l|}{ Etiology of liver cirrhosis } \\
\hline Chronic hepatitis C & $37(71.2)$ & $17(63)$ & 0.45 \\
\hline Chronic hepatitis B & $9(17.3)$ & $4(14.8)$ & 0.12 \\
\hline Autoimmune hepatitis & $3(5.8)$ & $3(11.1)$ & 0.38 \\
\hline Nonalcoholic steatohepatitis & $2(3.8)$ & $2(7.4)$ & 0.32 \\
\hline Cryptogenic & $1(1.9)$ & $1(3.7)$ & 0.29 \\
\hline \multicolumn{4}{|l|}{ Child-Pugh class } \\
\hline Child A & 0 & 0 & - \\
\hline Child B & $13(25)$ & $7(26)$ & 0.46 \\
\hline Child C & $39(75)$ & $20(74)$ & 0.15 \\
\hline MELD score & $11.3(10.5-18)$ & $11.1(10-17)$ & 0.34 \\
\hline \multicolumn{4}{|l|}{ Serum analysis } \\
\hline Alanine aminotransferase, IU/L & $75.5 \pm 22.33$ & $41.22 \pm 16.22$ & 0.02 \\
\hline Aspartate aminotransferase, IU/L & $44.55 \pm 12.64$ & $51.84 \pm 11.23$ & 0.75 \\
\hline Prothrombin time, sec & $20 \pm 1.4$ & $17 \pm 1.1$ & 0.04 \\
\hline Bilirubin, mg/dL & $0.86 \pm 0.16$ & $0.66 \pm 0.12$ & 0.52 \\
\hline Albumin, gm/dL & $2.8 \pm 1.1$ & $2.9 \pm 1.2$ & 0.66 \\
\hline Creatinine, mg/dL & $1.17 \pm 0.3$ & $0.66 \pm 0.18$ & 0.03 \\
\hline \multicolumn{4}{|l|}{ Ascitic fluid analysis } \\
\hline Polymorphonuclear leukocytes, $/ \mathrm{mm}^{3}$ & $1,560 \pm 755$ & $90 \pm 45$ & $<0.001$ \\
\hline Positive culture & 29 & 0 & - \\
\hline Protein, mg/dL & $465 \pm 120.22$ & $290.77 \pm 155.86$ & $<0.001$ \\
\hline
\end{tabular}

Data are presented as the mean \pm SD or number $(\%)$.

SBP, spontaneous bacterial peritonitis; MELD, Model for End-Stage Liver Disease. 
Patients with SBP had liver cirrhosis of different etiologies (Table 1). In all, 37 cases with chronic hepatitis $\mathrm{C}$ related cirrhosis (71.2\%), nine cases with chronic hepatitis B related cirrhosis (17.3\%), three cases with autoimmune-related cirrhosis (5.8\%), two cases with nonalcoholic steatohepatitis-related cirrhosis (3.8\%) and one case with cryptogenic cirrhosis (1.9\%). According to the Child-Pugh score; 13 (25\%) of the ascitic patients with SBP were classified as grade B and 39 of the patients (75\%) were classified as grade C. As regard Model for End-Stage Liver Disease scoring of SBP group; they were ranging from 10.5 to 18 (Table 1).

There was no significant difference regarding the age and sex between SBP and non-SBP patients. There was a significant increase in alanine aminotransferase, prothrombine time and serum creatinine in patients with SBP versus control group $(75.5 \pm 22.33 \mathrm{IU} / \mathrm{L}$ vs $41.22 \pm 16.22 \mathrm{IU} / \mathrm{L} ; 20 \pm 1.4 \mathrm{sec}$ vs $17 \pm 1.1$ sec; $1.17 \pm 0.3 \mathrm{mg} / \mathrm{dL}$ vs $0.66 \pm 0.18 \mathrm{mg} / \mathrm{dL}$, respectively). On the other hand, there was no statistically significant difference in aspartate aminotransferase, serum bilirubin and serum albumin (all p>0.05) (Table 1).

Ascitic fluid analysis revealed a statistically significant increase in PMN cells and protein content in SBP patients than non-SBP patients $\left(1,560 \pm 755 / \mathrm{mm}^{3}\right.$ vs $90 \pm 45 / \mathrm{mm}^{3} ; 465 \pm 120.22 \mathrm{mg} / \mathrm{dL}$ vs $290.77 \pm 155.86 \mathrm{mg} / \mathrm{dL}$, respectively; all $\mathrm{p}<0.001$ ) (Table 1).

Among 52 patients with SBP, 29 had positive ascitic fluid cultures; the organisms isolated were Escherichia coli (18 patients), Staphylococcus aureus (nine patients), and Klebsiella pneumoniae (two patients). The other patients (23 patients) with SBP only had PMN $>250 / \mathrm{mm}^{3}$ without positive bacteriological culture of ascitic fluid (Table 1).

\section{Serum PCT, ascitic calprotectin, serum and ascitic levels of TNF- $\alpha$, IL-6, and PMN in patients with and without SBP}

There was a statistically significant increase in serum PCT and ascitic calprotectin $(\mathrm{p}<0.001)$ in SBP patients versus nonSBP patients. As regard TNF- $\alpha$, there was a statistically significant increase in serum levels (55 [54-94] pg/mL vs 18 [16-35.5] $\mathrm{pg} / \mathrm{mL} ; \mathrm{p}<0.001$ ), and statistically increase in ascitic levels (98 [70-485] pg/mL vs 42.5 [25.5-65.9] pg/mL; $\mathrm{p}<0.001)$ in SBP versus non-SBP (Table 2).

As regards $\mathrm{IL}-6$, there was a statistically significant increase in serum levels in SBP versus non-SBP group (132 [54-556] ng/ $\mathrm{mL}$ vs 10.5 [7.45-27] ng/mL; $\mathrm{p}<0.001$ ), and statistically increase in ascitic levels (553 [432-956] ng/mL vs 195 [95-347] ng/mL; $\mathrm{p}<0.001$ ) (Table 2).

As regards PMN cell count, there is a statistically significant increase in serum levels $\left(8,590[4,450-14,560] / \mathrm{mm}^{3}\right.$ vs 5,270 $\left.[3,650-7,550] / \mathrm{mm}^{3} ; \mathrm{p}=0.032\right)$, and statistically significant increase in ascitic levels (543 [277-3,755]/ $\mathrm{mm}^{3}$ vs 25 [15-215]/ $\mathrm{mm}^{3} ; \mathrm{p}<0.001$ ) in SBP versus non-SBP group (Table 2 ).

\section{ROC curve analysis of serum PCT, PMN, and proinflam- matory cytokines (TNF- $\alpha$ and IL-6)}

As shown in Table 3 and Fig. 2, we found that at a cutoff value of $0.94 \mathrm{ng} / \mathrm{mL}$, serum PCT had a diagnostic sensitivity of 94.3\% and specificity 91.8\% for detecting SBP (AUC=0.941 with negative predictive values [NPV, 93\%] and positive predictive values [PPV, 95\%]).

Concerning serum PMN cell count, it was found that at a cutoff value of $8,100 / \mathrm{mm}^{3}$, serum PMN cell count had $85.7 \%$ sensitivity and $72 \%$ specificity for detecting SBP (AUC=0.811 with NPV [76\%] and PPV [78\%]). Also, at a cutoff value of 48.5 $\mathrm{pg} / \mathrm{mL}$, serum TNF- $\alpha$ had $90 \%$ sensitivity and $87.1 \%$ specificity for detecting SBP (AUC=0.961 with NPV [86\%] and PPV [78\%]). At a cutoff value of $151 \mathrm{ng} / \mathrm{mL}$, IL-6 had 86.5\% sensitivity and 83.5\% specificity for detecting SBP (AUC=0.922 with NPV [85\%] and PPV [79\%]).

Table 2. Serum Procalcitonin, Ascitic Calprotectin, and Serum and Ascitic Levels of TNF- $\alpha$, IL-6, and PMN in Patients with and without SBP

\begin{tabular}{|c|c|c|c|}
\hline Variable & SBP & Non-SBP & $\mathrm{p}$-value \\
\hline Serum procalcitonin, $\mathrm{ng} / \mathrm{mL}$ & $8.5(2.5-22)$ & $0.4(0.1-2.5)$ & $<0.001$ \\
\hline Ascitic calprotectin, ng/mL & $762.6(203.5-955.6)$ & $270.7(195.7-567.4)$ & $<0.001$ \\
\hline \multicolumn{4}{|l|}{$\mathrm{TNF}-\alpha, \mathrm{pg} / \mathrm{mL}$} \\
\hline Serum & $55(54-94)$ & $18(16-35.5)$ & $<0.001$ \\
\hline Ascitic fluid & $98(70-485)$ & $42.5(25.5-65.9)$ & $<0.001$ \\
\hline \multicolumn{4}{|l|}{ IL-6, ng/mL } \\
\hline Serum & $132(54-556)$ & $10.5(7.45-27)$ & $<0.001$ \\
\hline Ascitic fluid & $553(432-956)$ & 195 (95-347) & $<0.001$ \\
\hline \multicolumn{4}{|l|}{ PMNs, $/ \mathrm{mm}^{3}$} \\
\hline Serum & $8,590(4,450-14,560)$ & $5,270(3,650-7,550)$ & 0.032 \\
\hline Ascitic fluid & $543(277-3,755)$ & $25(15-215)$ & $<0.001$ \\
\hline
\end{tabular}

Data are presented as median (minimum-maximum).

TNF- $\alpha$, tumor necrosis factor $\alpha$; IL-6, interleukin 6; PMNs, polymorphonuclear leukocytes; SBP, spontaneous bacterial peritonitis. 
Table 3. Receiver Operator Characteristics Curve Analysis of Serum Procalcitonin, Ascitic Calprotectin, and Serum and Ascitic Levels of TNF- $\alpha$, IL-6, and PMN Patients with and without SBP

\begin{tabular}{|c|c|c|c|c|c|c|}
\hline Variable & AUC & Cutoff value & Se. & Sp. & NPV & PPV \\
\hline \multicolumn{7}{|l|}{ Serum levels } \\
\hline Procalcitonin, ng/mL & 0.941 & 0.94 & 94.3 & 91.8 & 93 & 95 \\
\hline TNF- $\alpha, p g / m L$ & 0.961 & 48.5 & 90 & 87.1 & 86 & 78 \\
\hline IL-6, ng/mL & 0.922 & 151 & 86.5 & 83.5 & 85 & 79 \\
\hline PMNs, $/ \mathrm{mm}^{3}$ & 0.811 & 8,100 & 85.7 & 72 & 76 & 78 \\
\hline \multicolumn{7}{|l|}{ Ascitic fluid analysis } \\
\hline Calprotectin, ng/mL & 0.921 & 445 & 95.4 & 85.2 & 93 & 71 \\
\hline $\mathrm{TNF}-\alpha, \mathrm{pg} / \mathrm{mL}$ & 0.951 & 67 & 90 & 83.6 & 65 & 87 \\
\hline $\mathrm{IL}-6, \mathrm{ng} / \mathrm{mL}$ & 0.969 & 545 & 96.2 & 75.4 & 89 & 76 \\
\hline PMNs, $/ \mathrm{mm}^{3}$ & 0.871 & 265 & 91 & 73.8 & 92 & 86 \\
\hline
\end{tabular}

Data are presented as percentage.

TNF- $\alpha$, tumor necrosis factor $\alpha$; IL-6, interleukin 6; PMNs, polymorphonuclear leukocytes; SBP, spontaneous bacterial peritonitis; AUC, area under the receiver operating characteristic curve; Se., sensitivity; Sp., specificity; NPV, negative predictive value; PPV, positive predictive value.

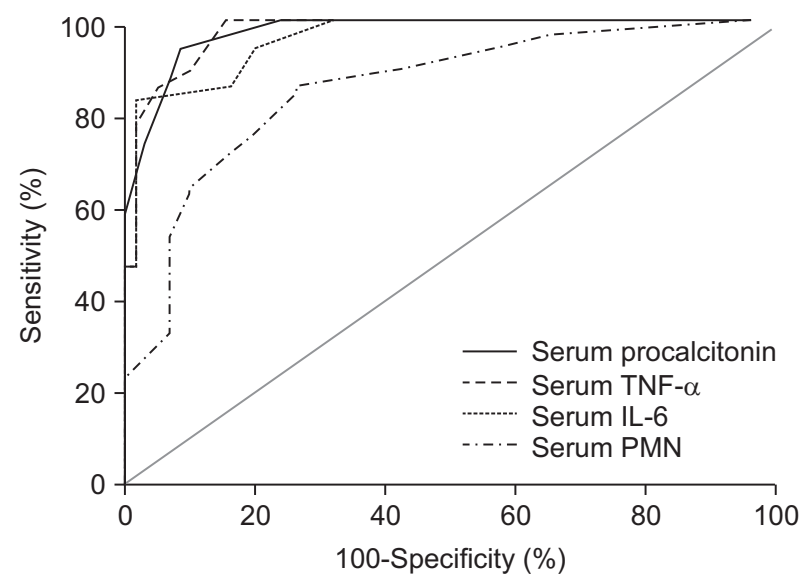

Fig. 2. Receiver operating characteristic curves of serum procalcitonin, tumor necrosis factor $\alpha(\mathrm{TNF}-\alpha)$, interleukin 6 (IL-6), and polymorphonuclear leukocytes (PMNs) in detecting ascitic fluid infection in cirrhotic patients.

\section{ROC curve analysis of ascitic calprotectin, PMN, and proinflammatory cytokines (TNF- $\alpha$ and IL-6)}

We detected that ascitic calprotectin, at a cutoff value of 445 $\mathrm{ng} / \mathrm{mL}$, had a diagnostic sensitivity of $95.4 \%$ and specificity 85.2\% for detecting SBP (AUC=0.921 with NPV [93\%] and PPV [71\%]). Moreover, ascitic PMN cell count at a cutoff value of $265 / \mathrm{mm}^{3}$ had $91 \%$ sensitivity and $73.8 \%$ specificity for detecting SBP (AUC=0.871 with NPV [92\%] and PPV [86\%]). Also, at a cutoff value of $67 \mathrm{pg} / \mathrm{mL}$, ascitic TNF- $\alpha$ had 90\% sensitivity and $83.6 \%$ specificity for detecting SBP (AUC $=0.951$ with NPV [65\%] and PPV [87\%]). Finally ascitic IL-6 at a cutoff value of $545 \mathrm{ng} / \mathrm{mL}$ had 96.2\% sensitivity and 75.4\% specificity for detecting SBP (AUC=0.969 with NPV [89\%] and PPV [76\%]) (Table 3, Fig. 3).

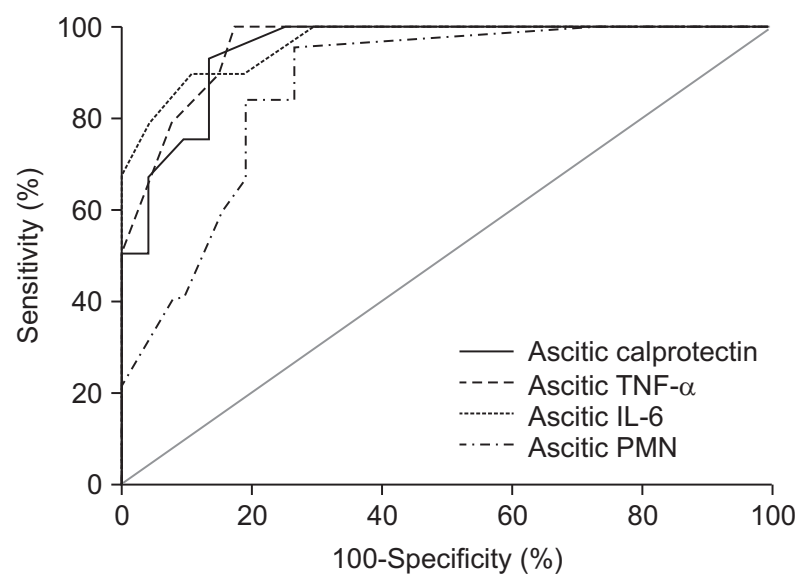

Fig. 3. Receiver operating characteristic curves of ascitic calprotectin, tumor necrosis factor $\alpha(\mathrm{TNF}-\alpha)$, interleukin 6 (IL-6), and polymorphonuclear leukocytes (PMNs) in detecting ascitic fluid infection in cirrhotic patients.

\section{Correlation between serum PCT and ascitic calprotectin with other proinflammatory cytokines (TNF- $\alpha$ and IL-6) and ascitic fluid contents}

For patients with SBP, Spearman correlation analysis declared that a significant positive correlation between TNF- $\alpha$ and IL- 6 levels, both in ascitic fluid (rho=0.79, $\mathrm{p}<0.001$ ) as well as in the serum (rho=0.69, $\mathrm{p}<0.001$ ). The ascitic fluid concentrations of TNF- $\alpha$ and IL- 6 were positively correlated with serum concentration of TNF- $\alpha$ and IL- 6 (for TNF- $\alpha$, rho=0.68, $\mathrm{p}<0.001$; for IL-6, rho=0.45, $\mathrm{p}=0.039$ ). An interesting finding was detected, which is a significant positive correlation between ascitic fluid calprotectin levels and serum levels of TNF- $\alpha$ and IL-6 (rho=0.50, $\mathrm{p}=0.015$ and $r h o=0.63, \mathrm{p}=0.012$, respectively). Also, there is a significant positive correlation between serum PCT levels 
and serum levels of TNF- $\alpha$ and IL-6 (rho=0.51, p=0.011 and $r h o=0.40, \mathrm{p}=0.047$, respectively). Moreover, a significant positive correlation between serum PCT levels with ascitic fluid protein content and ascitic PMN ( $r h o=0.61, \mathrm{p}=0.043$ and $r h o=0.59$, $\mathrm{p}=0.038$, respectively). Moreover, there is a significant positive correlation between ascitic fluid calprotectin levels with ascitic fluid protein content and ascitic PMN (rho=0.55, p=0.033 and $r h o=0.51, \mathrm{p}=0.028$, respectively).

\section{DISCUSSION}

SBP is a very common bacterial infection in patients with cirrhosis and ascites. ${ }^{15}$ SBP pathogenesis in patients with cirrhosis is considered to be the main consequence of bacterial translocation (BT). The BT is the process through which viable or nonviable bacteria and bacterial products (bacterial DNA or endotoxins) cross the intestinal lumen and come into the mesenteric lymph nodes or extraintestinal. Bacterial translocation also is involved in increasing the hyperdynamic state of cirrhosis and in aggravation of hemostasis disorders. ${ }^{16}$ Although alternative method using mean platelet volume, C-reactive protein, and white blood cell levels measurement can be considered an accurate diagnostic test in predicting SBP, possibly because of a continuous systemic inflammatory response, ${ }^{17}$ the diagnosis of SBP is still based on diagnostic paracentesis. ${ }^{18}$ It is an evasive maneuver with some complications. Therefore, there is a need for other noninvasive diagnostic tools.

PCT levels may be useful to distinguish bacterial infections from nonbacterial infections. ${ }^{19}$ It does not rise significantly with viral or noninfectious inflammations. Some studies reported that severe infection with an associated systemic response may bring the blood levels of PCT up to $100 \mu \mathrm{g} / \mathrm{L}$.

In this study, there is a significant increase in serum PCT in SBP versus non-SBP group. This is in accordance with Cekin et al. ${ }^{14}$ who reported the same results.

In our patients, we reported that at a cutoff value of $0.94 \mathrm{ng} /$ $\mathrm{mL}$, serum PCT had 94.3\% sensitivity and 91.8\% specificity for detecting SBP, AUC=0.941 with NPV and PPV values for serum PCT 93\% and 95\%, respectively. Moreover, there is a positive correlation between serum PCT and other proinflammatory cytokines (TNF- $\alpha$ and IL-6) supported the hypothesis that, serum PCT could reflect ongoing systemic inflammatory responses in cirrhotic patients with AFI. According to this finding, we could hypotheses that serum PCT not only represents BT and multiplications of microorganisms especially gram negative species, but also systemic inflammation and infection through cascades of proinflammatory cytokines release in the course of disease progression. This finding may be in accordance with Viallon et $a l^{7}$ who reported merely the same findings.

The cornerstone of the diagnosis of SBP stills the ascitic fluid analysis with the PMN cell count. Albillos et al. ${ }^{20}$ reported that an ascitic fluid PMN count greater than $500 / \mathrm{mm}^{3}$ had specific- ity and sensitivity of 98\% and 90\%, respectively. In our study, at a cutoff value of $265 / \mathrm{mm}^{3}$, ascitic PMN cell count had 91\% sensitivity and 73.8\% specificity for detecting SBP (AUC=0.871 with NPV [92\%] and PPV [86\%]).

In our cirrhotic patients with ascitis, we found high specificity and sensitivity for serum PCT levels in patients with SBP, as discussed before. From our point of view, these values may be considered as an accurate and rapid method for detection of SBP in clinical practice and have similar accuracy in the determination of the PMN cell counts in ascitic fluid.

In contrast, Lesińska et al. ${ }^{21}$ found that serum PCT levels did not distinguish between patients with and without SBP. In patients with decompensated cirrhosis signs of systemic inflammatory response are usually lacking even in life-threatening infections. So, PCT has very large area of overlapping results and low sensitivity for SBP diagnosis especially in these groups.

The function of calprotectin is not fully known, but an antimicrobial activity has been shown. Calprotectin inhibits growth of E. coli, S. aureus, Staphylococcus epidermidis, Klebsiella spp., and Candida spp. at minimum inhibitory concentrations that in some cases are lower than the levels found in plasma of patients with bacteremia. Killing is seen at concentrations two to four times the minimum inhibitory concentrations. ${ }^{22}$

In this study, ascitic fluid calprotectin was found to be significantly elevated in patients with SBP compared to non-SBP patients. This result is inconsistent with those demonstrated by Elbanna et $a .^{23}$ and Ali et al. ${ }^{24}$

A significant positive correlation was observed between ascitic fluid calprotectin and ascitic fluid protein and PMN cell count. A study conducted by Ali et al. ${ }^{24}$ found a significant correlation between ascitic fluid calprotectin and PMN cell count. Burri et al. ${ }^{10}$ reported that ascitic calprotectin levels correlated well and reliably with PMN count. Samples with PMN >250/ $\mathrm{mm}^{3}$ also had higher ascitic calprotectin levels than the samples with PMN $\leq 250 / \mathrm{mm}^{3}$. Moreover, there is a significant positive correlation between ascitic fluid calprotectin levels and serum levels of TNF- $\alpha$ and IL-6.

The present study demonstrated that ascitic fluid calprotectin at a cutoff value of $445 \mathrm{ng} / \mathrm{mL}$ had $95.4 \%$ specificity and $85.2 \%$ sensitivity for detecting SBP. Burri et al. ${ }^{10}$ reported that at a cutoff value of $0.63 \mu \mathrm{g} / \mathrm{mL}$, ascitic calprotectin yielded a sensitivity of 95\% and a specificity of 70\% for diagnosis of SBP.

SBP is associated with an increase in proinflammatory cytokines TNF- $\alpha$ and IL- 6 and may be associated with development of renal impairment, thus indicating poor prognosis in these patients. ${ }^{25}$ This elevation could be antagonist by the concomitant elevation of several anti-inflammatory factors (IL-10, soluble IL-1 receptor antagonist, soluble receptors of TNF p55 and p75 and soluble receptor of IL-6) suggest a regulatory control of the inflammatory process by these molecules. Moreover, elevated levels of anti-inflammatory molecules in patients with bacterial ascites and elevated proinflammatory molecules could be 
interpreted as a mechanism of protection in those patients with the higher levels of proinflammatory compounds. ${ }^{26}$ IL- 6 is a counter-regulatory, anti-inflammatory cytokine of the proinflammatory cytokine TNF- $\alpha .^{27}$ In our cirrhotic patients, IL-6 is produced in ascitic fluid and there is a marked increase in the local production during an episode of bacterial peritonitis (SBP). All these suggest that IL- 6 might participate in inflammatory action. ${ }^{26}$ This is in accordance with Souza et al. ${ }^{28}$ who reported the same observation. In addition, at a cutoff value of $545 \mathrm{ng} /$ $\mathrm{mL}$, ascitic IL-6 had 96.2\% sensitivity and 75.4\% specificity for detecting SBP (AUC=0.969 with NPV [89\%] and PPV [76\%] for ascitic IL-6).

TNF- $\alpha$ is a macrophage derived cytokine, generated in major amounts in response to endotoxin. Since SBP is considered to be the consequence of repeated episodes of bacteremia following intestinal BT with seeding of ascitic fluid, and also the intermittent presence of bacteria in blood may be followed by an activation of the cytokine cascade. ${ }^{29}$ In our study, high ascitic fluid levels of TNF- $\alpha$ have been observed in our patients with SBP, this is in consistent with Odeh et $a{ }^{30}{ }^{30}$ who found the same finding. Moreover, at a cutoff value of $67 \mathrm{pg} / \mathrm{mL}$, ascitic TNF- $\alpha$ had 90\% sensitivity and 83.6\% specificity for detecting SBP (AUC=0.951 with NPV [65\%] and PPV [87\%] for ascitic TNF- $\alpha$ ).

This prospective study evaluated the diagnostic utility of measuring serum PCT, ascitic fluid calprotectin and proinflammatory cytokines (TNF- $\alpha$ and IL-6) in both serum and ascitic fluid to identify ascitic PMN counts $>250 / \mathrm{mm}^{3}$ in patients referred for paracentesis, and provides the following new data: patients with an elevated PMN count $\left(>250 / \mathrm{mm}^{3}\right.$ ) had higher serum PCT, ascitic calprotectin levels and proinflammatory cytokines in both serum and ascitic fluid than those with normal cell counts; this finding indicates that serum PCT and ascitic fluid calprotectin correlate well and reliably with PMN cell count. It is clinically significant that serum PCT and ascitic calprotectin levels in patients can identify elevated PMN counts. Indeed, serum PCT and ascitic calprotectin may serve as a surrogate marker for PMN count and would be amenable to routine SBP screening, especially when measured by a bedside tests as rapid and accurate assay.

There are different limitations to the current study that merit consideration. First, we included all patients with ascites, irrespective of the etiology, and it may be that our results cannot be popular to all patients with liver cirrhosis. Second, our sample size was comparatively small, and we will need larger studies to evaluate this test in different clinical settings and to establish a reliable cutoff for serum PCT and ascitic calprotectin for optimal identification of PMN counts $>250 / \mathrm{mm}^{3}$.

In conclusion, both serum PCT and ascitic fluid calprotectin were significantly elevated in cirrhotic ascitic patients with SBP versus non-SBP patients. In addition, they were positively correlated well with the PMN cell count, protein levels in ascitic fluid and proinflammatory cytokines levels (TNF- $\alpha$ and IL-6) and my used as reliable bedside available tests for diagnose SBP. These tests are interpretable within 2 hours, or recently available bedside tests. Our study recommended a large randomized studies to confirm the diagnostic role of serum PCT and other inflammatory markers regarding the survival outcome in patients with SBP.

\section{CONFLICTS OF INTEREST}

No potential conflict of interest relevant to this article was reported.

\section{ACKNOWLEDGEMENTS}

We would like to express our sincere gratitude to the patients and staff of the Tropical Medicine, Medical Microbiology and Immunology, and Clinical Pathology Departments for their valuable efforts.

\section{REFERENCES}

1. Brann OS. Infectious complications of cirrhosis. Curr Gastroenterol Rep 2001;3:285-292.

2. Mousa N, Abdel-Razik A, El-Nahas H, et al. Cryptosporidiosis in patients with diarrhea and chronic liver diseases. J Infect Dev Ctries 2014;8:1584-1590.

3. Iqbal J, Hira PR, Al-Ali F, Khalid N. Cyclospora cayetanensis: first report of imported and autochthonous infections in Kuwait. J Infect Dev Ctries 2011;5:383-390.

4. Snelling WJ, Xiao L, Ortega-Pierres G, et al. Cryptosporidiosis in developing countries. J Infect Dev Ctries 2007;1:242-256.

5. Thuluvath PJ, Morss S, Thompson R. Spontaneous bacterial peritonitis: in-hospital mortality, predictors of survival, and health care costs from 1988 to 1998. Am J Gastroenterol 2001;96:12321236.

6. Dandona P, Nix D, Wilson MF, et al. Procalcitonin increase after endotoxin injection in normal subjects. J Clin Endocrinol Metab 1994;79:1605-1608.

7. Viallon A, Zeni F, Pouzet V, et al. Serum and ascitic procalcitonin levels in cirrhotic patients with spontaneous bacterial peritonitis: diagnostic value and relationship to pro-inflammatory cytokines. Intensive Care Med 2000;26:1082-1088.

8. Schäfer BW, Heinzmann CW. The S100 family of EF-hand calcium-binding proteins: functions and pathology. Trends Biochem Sci 1996;21:134-140.

9. Jung SY, Park YB, Ha YJ, Lee KH, Lee SK. Serum calprotectin as a marker for disease activity and severity in adult-onset Still's disease. J Rheumatol 2010;37:1029-1034.

10. Burri E, Schulte F, Muser J, Meier R, Beglinger C. Measurement of calprotectin in ascitic fluid to identify elevated polymorphonuclear cell count. World J Gastroenterol 2013;19:2028-2036.

11. Navasa M, Follo A, Filella X, et al. Tumor necrosis factor and 
interleukin-6 in spontaneous bacterial peritonitis in cirrhosis: relationship with the development of renal impairment and mortality. Hepatology 1998;27:1227-1232.

12. Kim JK, Chon CY, Kim JH, et al. Changes in serum and ascitic monocyte chemotactic protein-1 (MCP-1) and IL-10 levels in cirrhotic patients with spontaneous bacterial peritonitis. J Interferon Cytokine Res 2007;27:227-230.

13. Moore KP, Aithal GP. Guidelines on the management of ascites in cirrhosis. Gut 2006;55 Suppl 6:vi1-vi12.

14. Cekin Y, Cekin AH, Duman A, Yilmaz U, Yesil B, Yolcular BO. The role of serum procalcitonin levels in predicting ascitic fluid infection in hospitalized cirrhotic and non-cirrhotic patients. Int J Med Sci 2013;10:1367-1374.

15. Wong F, Bernardi M, Balk R, et al. Sepsis in cirrhosis: report on the 7th meeting of the International Ascites Club. Gut 2005;54:718725.

16. Wiest R, Garcia-Tsao G. Bacterial translocation (BT) in cirrhosis. Hepatology 2005;41:422-433.

17. Abdel-Razik A, Eldars W, Rizk E. Platelet indices and inflammatory markers as diagnostic predictors for ascitic fluid infection. Eur J Gastroenterol Hepatol 2014;26:1342-1347.

18. Rimola A, Gracía-Tsao G, Navasa M, et al. Diagnosis, treatment and prophylaxis of spontaneous bacterial peritonitis: a consensus document. International Ascites Club. J Hepatol 2000;32:142-153.

19. Schuetz P, Christ-Crain M, Thomann R, et al. Effect of procalcitonin-based guidelines vs standard guidelines on antibiotic use in lower respiratory tract infections: the ProHOSP randomized controlled trial. JAMA 2009;302:1059-1066.

20. Albillos A, Cuervas-Mons V, Millán I, et al. Ascitic fluid polymorphonuclear cell count and serum to ascites albumin gradient in the diagnosis of bacterial peritonitis. Gastroenterology 1990;98:134140.

21. Lesińska M, Hartleb M, Gutkowski K, Nowakowska-Duława E. Procalcitonin and macrophage inflammatory protein-1 beta (MIP-
1 beta) in serum and peritoneal fluid of patients with decompensated cirrhosis and spontaneous bacterial peritonitis. Adv Med Sci 2014;59:52-56.

22. Steinbakk M, Naess-Andresen CF, Lingaas E, Dale I, Brandtzaeg P, Fagerhol MK. Antimicrobial actions of calcium binding leucocyte L1 protein, calprotectin. Lancet 1990;336:763-765.

23. Elbanna A, Allam N, Hossam N, Ibrahim A, Wagdy M. Plasma and ascitic fluid level of calprotectin in chronic liver disease malignant and non-malignant. Alexandria Bulletin 2008;647-653.

24. Ali AG, Ahmed NS, Hasan SM. Calprotectin measurement in ascitic fluid: a new test for the rapid diagnosis of spontaneous bacterial peritonitis. Med J Cairo Univ 2013;81:53-56.

25. Park MI, Song BC, Yang SH, et al. Tumor necrosis factor-a and interleukin- in ascitic fluid and plasma in spontaneous bacterial peritonitis. Korean J Hepatol 1999;5:314-321.

26. Rodríguez-Ramos C, Galan F, Díaz F, Elvira J, Martín-Herrera L, Girón-González JA. Expression of proinflammatory cytokines and their inhibitors during the course of spontaneous bacterial peritonitis. Dig Dis Sci 2001;46:1668-1676.

27. Zhang W, Yue B, Wang GQ, Lu SL. Serum and ascites levels of macrophage migration inhibitory factor, TNF- $\alpha$ and IL-6 in patients with chronic virus hepatitis B and hepatitis cirrhosis. Hepatobiliary Pancreat Dis Int 2002;1:577-580.

28. Souza MH, Cunha FQ, Martinelli AL. Interleukin 6 concentration in ascitic fluid of cirrhotic patients: relationship with previous episodes of spontaneous bacterial peritonitis. J Gastroenterol 2003; 38:149-152.

29. Such J, Hillebrand DJ, Guarner C, et al. Tumor necrosis factor- $\alpha$, interleukin-6, and nitric oxide in sterile ascitic fluid and serum from patients with cirrhosis who subsequently develop ascitic fluid infection. Dig Dis Sci 2001;46:2360-2366.

30. Odeh M, Sabo E, Srugo I, Oliven A. Serum levels of tumor necrosis factor- $\alpha$ correlate with severity of hepatic encephalopathy due to chronic liver failure. Liver Int 2004;24:110-116. 